\title{
Teaching of Science and Mathematics in Pre-Schools of Botswana: The Existing Practices
}

\author{
Kabita Bose ${ }^{1}$, Marea Tsamaase ${ }^{2}$, Grace Seetso ${ }^{3}$ \\ ${ }^{1}$ Department of Primary Education, University of Botswana, Gaborone, Botswana \\ ${ }^{2}$ Department of Family and Consumer Sciences, University of Botswana, Gaborone, Botswana \\ ${ }^{3}$ Department of Primary Education, University of Botswana, Gaborone, Botswana \\ Email: bose@mopipi.ub.bw,TSAMAASE@mopipi.ub.bw, Grace.Seetso@mopipi.ub.bw
}

Received April 18 ${ }^{\text {th }}$, 2013; revised May 20 $0^{\text {th }}$ 2013; accepted May $28^{\text {th }}, 2013$

\begin{abstract}
Copyright (c) 2013 Kabita Bose et al. This is an open access article distributed under the Creative Commons Attribution License, which permits unrestricted use, distribution, and reproduction in any medium, provided the original work is properly cited.
\end{abstract}

\begin{abstract}
The study aims to examine the state of mathematics and science education in pre-schools of Botswana. The study intended to find out the knowledge base of the teachers, the content and the process of activities that were carried out in pre-schools, and also gauged availability and usage of resources in pre-schools, while identifying the challenges faced and the strategies used to overcome by the teachers, in carrying out Maths and Science activities. The study adopted both quantitative and qualitative approaches. The research was done using survey questionnaire and observation techniques and was conducted in 26 pre-schools in Gaborone. The sample comprised of 64 teachers and 17 administrators who were identified by using purposive sampling techniques. Quantitative data was also analysed using SPSS version 20, and responses to Open-ended questions were analysed qualitatively. The findings showed that the trained teachers although not in ECE, claimed to have some knowledge base of mathematics and science, and identified pedagogy to be more important than content, for teaching science and mathematics at ECE. They however, were of the view that ECE teacher training influences the knowledge base of the teachers, and hence specialised training in ECE is necessary. The study also showed that mathematics activities were predominant in the pre-schools as compared to science activities; the teachers frequently engaged in mathematics and science activities outdoors; and the mathematics and science corners that were available in most centres, were not utilised adequately. It further revealed that an equal number of the teachers, i.e. almost half of them, faced challenges while teaching mathematics and science in pre-schools, as those who did not. The study therefore recommended ECE teachers' professional training on knowledge, pedagogy and content; and the menu to include more indoor and science activities.
\end{abstract}

Keywords: Early Childhood Education; Science and Mathematics Education; Pre-Schools; Botswana; Science and Mathematics Knowledge

\section{Introduction}

Children are active explorers of their environments, and learn, as well as construct their own knowledge by doing and discovering (Essa, 2011). Their understanding of scientific and mathematical concepts grows during Early Childhood (EC). Through exploration, process of inquiry and discovery, children get stimulation and encouragement to form concepts and develop thinking, classify information, opportunities to reason, solve problems and make decisions, rather than memorizing isolated scientific and mathematical concepts.

Children are curious and interested in exploring, which motivates them for learning. They can learn about emerging mathematical and scientific concepts and can be encouraged to develop scientific thinking. They learn all the time through play and interaction with their surrounding environment, which can form an important base for all teaching/learning process of maths and science (Johansson \& Pramling Samuelsson, 2006). The creation of an early enthusiasm in Mathematics and Science during this impressionable age, thus, must be laid, as the roots of later competence which are often established long before their school age. It may even start in toddlers who can be young explorers, as they use informal mathematical knowledge developed before they enter school to organise their environment. In fact Mathematics in early childhood classrooms begins with play and develops naturally as children interact with one another (Moomaw, 2011).

Learning and teaching mathematical and science concepts or/and ideas should form an integral part of daily life activities in EC, and should be part of the core curriculum. Activities that involve exploration and problem solving should be chosen as they display higher gains in various domains. Activities that help children focus their observation skills and provide classification experiences through exploration of number, length, area, volume, weight, colour, function, shape, geometric features, patterns, and texture should be chosen carefully. During early years, children need hands-on materials to believe and see it happen, as science is not intuitive (Gallenstein, 2004).

Science process skills may include the ability to ask questions, recognize relevant details, and use a combination of ob- 
servation and inference to generate evidence-based explanations. It should also be able to control variables, generate and interpret evidence, formulate models, measure and communicate ideas whilst clarifying meaning, classifying and predicting and recognising causality. These skills should enable one understand ideas like uncertainty, probability, necessity, and sufficiency, form and test a hypothesis, and should finally be able to design experiments and revise hypotheses (Lehrer \& Schauble, 2006).

They can use certain tools that enable testing of various concepts of living and non-living things. Counting, measuring, locating and designing, playing and explaining and such other activities should be made an integral part of children's everyday life, bearing in mind that they can have similarities between different geographic and cultural groups, and yet, can be distinctive (Bishop, 1991).

Experiences of mathematical and science concepts that children encounter in everyday life activities and interaction are rich. In essence, children enter preschool with a range of concepts gathered from informal experiences (Darling-Hammond, 2000). Hence educators need to discern and use them in teaching/learning process. Careful choices of activities that incorporate children's interests in the world around them, both in the classroom and outside, can promote all domains of learning. Early educators need to design the learning environment, that gives children opportunities to develop fundamental values, skills and understanding of different aspects, for example to develop understanding of basic properties of numbers, weight, etc. Nevertheless, availability of resources alone is inadequate as quality instruction demands both relevant resources and time to use those (Clement, 2001). Research shows that children do not have enough exposure to Maths oriented activities, neither at home nor at school (Moomaw, 2011).

Knowledge of pre-school curriculum and how to implement the ideas in everyday activities are important for EC teachers (Brenneman, 2011). They should have the knowledge of children's different ways of experiencing/learning/understanding, and emphasis should be laid on didactic knowledge (what, why, how, for whom, when) as well as the knowledge of context. Essentially teachers' content knowledge has a huge bearing on the way they present content to learners (Kallery \& Psillos, 2001). Furthermore, "teachers who have greater knowledge of teaching and learning are more highly rated and are more effective with students, especially at tasks requiring higher order thinking and problem solving” (Darling-Hammond, 2000: p. 167).

Teachers need to play an important role in planning, supporting and guiding children to learn about maths and science concepts through the use of various teaching strategies and techniques such as asking open-ended questions of what/how/ why; modelling; giving feedback; and cognitive structuring, in an environment that encourages learning through social relationships (Fu, 2010). Teaching strategies need to be, thus innovative and ground-breaking, that not only warrants novelty, but also facilitates early understanding and interest, and enables mastery of concepts. The instructors also need to take children's prior knowledge into consideration in order to understand children's experiences and use that as a point of departure (Glasserfeld, 1989; Resnick, 1987). The pedagogical orientation of Te Whaariki requires the teacher to share understandings in the role of active participator with children. Smith, Grima, Gaffney, and Powell (2000) in Garbett (2003) clarify this role by saying that:

Teachers do not simply transmit knowledge to passively receiving children, but they share meanings and understandings, and children take an active and inventive role (p. 468).

In addition, they need to use the state of the art multi-media technology that could foster interest and curiosity, rather than depending solely on traditional materials (Bers \& Portsmore, 2005). For a quality EC programme, the caregivers need to provide a developmentally appropriate context that progressively increases in conceptual depth and complexity as children advance through school and life (Lind, 1999; Bose, 2008).

It could thus be advocated that the existing practices in EC Education (ECE) settings, with the right choice of activities, strategies, and the application of developmentally appropriate programmes would certainly ensure the promotion of scientific thinking and mathematical skill development. Early childhood practitioners are viewed as having a specialised body of knowledge. This includes knowledge about children, teaching, learning and the curriculum that can be translated into meaningful practice. In addition, the teacher must plan learning experiences that engage and challenge children in thinking that is conceptually rich, coherently organised, and persistently knowledge building. An effective early childhood teacher should be one who can facilitate and extend children's learning within the holistic nature of the early childhood curriculum without being overcome by the traditional notions of teaching (Edwards \& Knight, 2000).

The question thus arises as What are the Existing Practices in ECE Settings? In the curriculum area of science this is particularly difficult since teachers often do not have the requisite background knowledge to integrate content and pedagogy on their own.

Research has underscored the importance of developing and nurturing mathematics and science skills at a tender age. Whatever evidence is available is based largely on studies that are carried out in developed countries, where ECE is comparatively at an advanced stage, as compared to the developing ones. In developing countries like Botswana, thus, a lot of scope is there, which differ significantly, both economically and cultureally, from that of a developed country. Hence this variance limits generalization of current literature on mathematics and science in EC. The researchers, therefore, found it worthwhile to undertake a study in Botswana, on the existing practices in pre-schools, as it is often found that the pupils either deny opting for Maths and/or Science subjects when they grow older, or do not fare well if opted for it at all! They felt that such a study would provide empirical data so as to contribute to the existing body of research regarding the teachers' knowledge base and the children's engagement in mathematical and scientific experiences.

It was also felt by the researchers that such a study would come at an opportune time, when the Ministry of Education and Skills Development (MoE \& SD) in Botswana was piloting the first Pre-Primary Curriculum Framework that was developed as a national guide; and the findings of the study would thus, contribute to the development of a robust curriculum that could ensure provision of developmentally appropriate experiences for young children.

\section{Aim}

The aim of the research study was to examine the existing 
practices in terms of mathematics and science education in pre-schools of Botswana.

\section{Objectives}

The research objectives of the study were to find out the:

1) Knowledge Base of the teachers in Mathematics and Science subjects;

2) Maths and Science activities carried out in pre-schools;

3) Availability of resources and their usage in pre-schools;

4) Challenges faced in carrying out Mathematics and Science activities and the strategies used to overcome them.

\section{Methodology}

A methodology is a set of methods and principles which are used to carry out research (Wiersma \& Jurs, 2005). For this study, a survey research design is used since it enables data to be collected from a fairly large sample that was scattered throughout Botswana. The research design involved both quantitative as well as qualitative paradigms and a survey questionnaire was used to collect data as questionnaires are more easily administered and are less expensive when compared to other modes of collecting data. Observations also formed an important part of the project. Purposive sampling technique was used to identify respondents for the study. From a total of 80 ECE centres, $1 / 3^{\text {rd }}$ of ECD centres formed part of the study 64 pre-school teachers participated in the questionnaire from Gaborone, the capital of Botswana. The questionnaires were distributed to teachers and were self-administered, with the assistance of a research assistant who also was trained for the task. The completed questionnaires were then collected after one week. Quantitative data was cleaned, coded, entered and analysed using SPSS (Statistical Package for Social Sciences) ver- sion 20. Responses to Open-ended question were categorized as per themes and verbatim reports were used descriptively.

\section{Results and Discussions}

\section{Demographic Data}

The results show that $80 \%$ had formal teaching qualifications, and possessed various credentials. Almost half of the population $(44 \%)$ was holding certificates, around $1 / 3^{\text {rd }}(31 \%)$ was holding diploma; and only 5\% was holding undergraduate degrees. However, the concern is that only $14 \%$ of the trained teachers received a formal training in ECE and possessed either a certificate or a diploma in ECE. The majority was trained either in Maths/Science or in other areas, but not in ECE (Figure 1).

This reiterates the issue of untrained teachers teaching in preschools, who lack knowledge of child development and various developmental aspects of young children. An emphasis thus needs to be laid on a specialised, professional teacher training in ECE, both at pre-service as well as in-service levels, in order to make a difference in teaching/learning process in ECE.

The study also shows that $13 \%$ were teachers with Standard 7, Junior Certificate and Form 2 to Form 5 (qualifications; and most of the certificate and diploma holders were below 45 year olds (Figure 1). So the encouraging thing is that most of them could perhaps be sent for an upgradation in their qualifications.

\section{Knowledge Base in Maths/Science}

In order to find out the existing practices, the researchers felt the need to find out the knowledge base of the participants of the study. So, the teachers were asked probing questions about their preparations through teacher training programmes to teach Maths/Science in ECE. The majority (84\%) however felt that

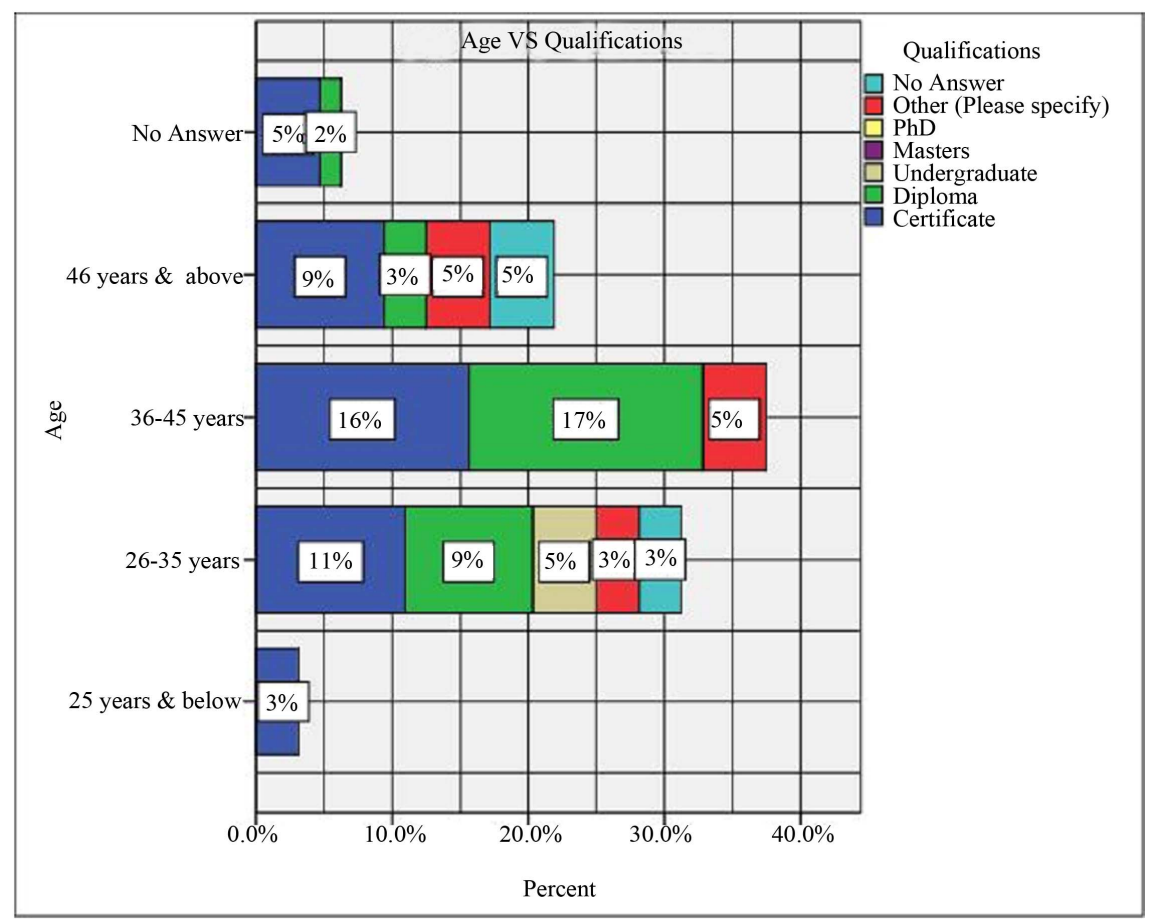

Figure 1.

Age and qualifications. 
they had the knowledge of teaching mathematics and science to children. Out of that, $75 \%$ said that the teacher training programmes prepared them in teaching of Maths and Science in ECE as they had attended teacher training programmes or workshops/short courses which trained them thoroughly (Figure 2).

On probing further, the respondents revealed that they had attended various training programmes, workshops/short courses like integrated courses for Nursery and Kindergarten, specialisation in Infant education, which trained them on child psychology, learning in the early years, language development, play-way method, curriculum development and instructions, learning strategies, lessons planning, outcome based education, Montessori method, life skills, numbering games, creative activities, communication skills, sensorial education, exercises of practical life, environmental science, pre-maths/pre-science, geometry, arithmetic, number formation and numeracy, health \& nutrition, first aid, living together, production of teaching aids, through discovery and simple experiments, etc.

A very small percentage (6\%), however, did not feel that the training prepared them in teaching of Maths/Science in ECE. On asking them further, to identify the items that teacher education programs could have included to equip them with the essential skills, they failed and could not clearly spell them out.

In order to find out about the knowledge base of the teachers, they further were asked about how easy or difficult it was to gain knowledge about individual childrens' experiences. Two thirds of the respondents (65.62\%) found it quite easy $(14.06 \%$ $+51.56 \%)$ to gain knowledge about individual children's experiences (Figure 3).

The teachers were also asked the necessary things that ECE teachers need to know, for teaching of mathematics and science. Almost 85\% rated Level of Students' Understanding and Organising Teaching Concepts as most necessary for teachers to know in teaching of Maths/Science to young children. Between $60 \%$ - 70\% thought New Knowledge about the Concept, Clear
Knowledge of Teaching Process and Knowledge of What Children Should Learn as necessary, whereas items like Factors Affecting Teaching, What Students Need to Know, and Background of Students with respect to Context were seen necessary roughly by $50 \%$. Less than half of them (45\%) saw the knowledge of Difficulties/Limitation Connected with Teaching an Idea as necessary for the teachers (Figure 3).

The results thus show that the teachers had some knowledge base and gave a clear verdict of pedagogy being more important that content, for teaching science and mathematics at ECE. But the fact that the teachers thought, that gathering knowledge about individual childrens' experiences was easy, and yet were unable to identify the items necessary for equipping ECE teachers with skills, perhaps indicates that it was out of their purview to outline them, and they need specialised training in ECE.

\section{Maths and Science Activities Done in Pre-Schools}

The next task was to find out about activities that were carried out in ECE centres. Around $85 \%$ of respondents said that they engaged in various activities to hone children's mathematical and science skills. On probing further, it was found that majority (64\%) did maths activities like number concepts, exploring numbers, counting numbers orally, writing numbers, sorting, classifying, sequencing, matching, identifying, ordering, addition, subtraction, sets, measuring, etc. This also shows that the teachers generally limited young childrens' ability in geometry and spatial relations, algebraic thinking and data analysis (NIEER, 2009) which is paramount in young children.

It also surfaced that mathematics activities were predominant as compared to science activities. Only $16 \%$ indicated that they indulged in science related activities like seasons, weather, mass, volume, sources of light, balancing, plantation, living \& non-living things, body parts, sounds, seed planting, use of human senses, gardening, sand games, nature walks, activities

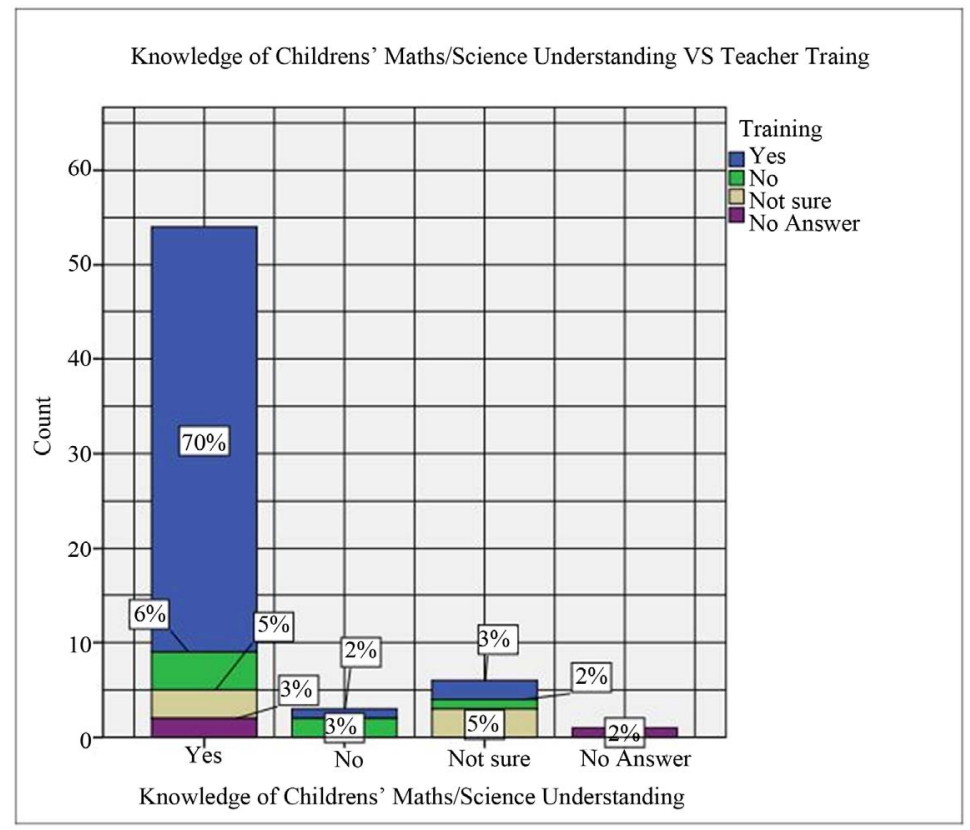

Figure 2.

Knowledge of teachers' understanding and training. 

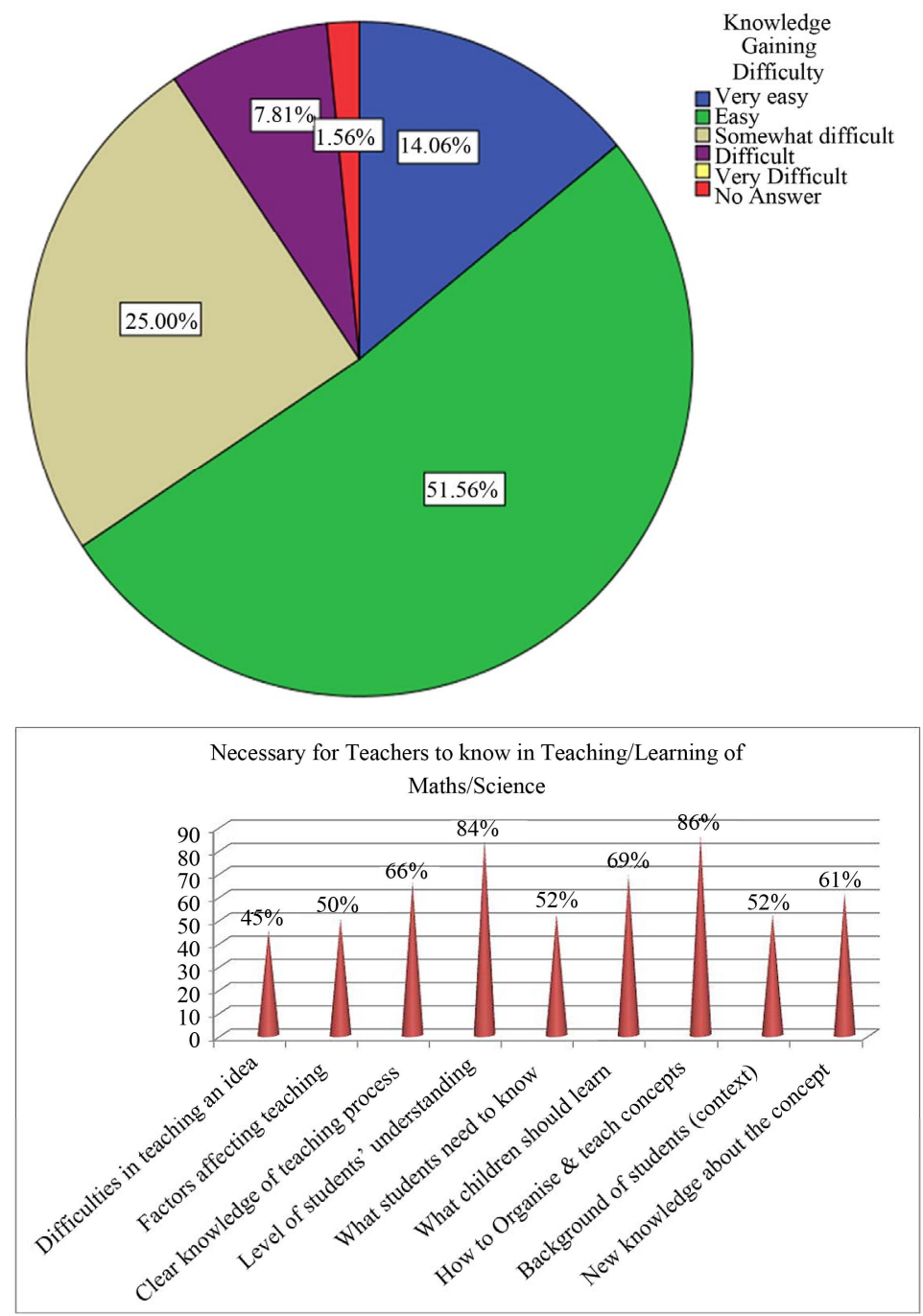

Figure 3.

Necessary knowledge for teachers.

related to hygiene, road safety etc. It also revealed that certain pertinent activities like time and length were sparingly used in pre-schools and very few engaged in experiments, explorations and observations, field trips, nature walk and spontaneous outdoor play.

A conspicuous absence of songs/rhymes and water play for teaching of mathematics and science in pre-schools was also revealed.

It was further revealed that (Figure 4) the majority of them (84\%) did the activities outdoors, and nothing much was done inside the classrooms using the maths/science corners. Probably, lack of training in ECE guided them to pick up the Mathematics and Science activities like nature walk, visit to water sources, see physical features, go for excursions, to take children outside the classroom as suggested in the pre-primary curricular framework (Republic of Botswana, 2008). But the brighter side was, almost half of them (53\%) did them every day.

To probe further, the teachers and the administrators were also asked Why Science Activities are not done as much as the Mathematics Activities in pre-schools, and the responses gathered were as follows:
- Math can be easily broken down;

- It is easier to teach as compared to science;

- Math related materials are easier to find;

- Math activities are not demanding;

- Science learning materials are difficult to find;

- Background and concept of maths are formed from daily home activities;

- Teachers think maths is more important than science;

- Teachers regard science as difficult and a high order thinking subject;

- Teachers incorporate science in maths;

- Society pressurises teachers to teach maths rather than science.

This shows that teachers need training, especially in teaching science and in providing science related activities in a simpler manner.

\section{Availability of Resources and Their Usage}

The researchers then tried find out the resources available in an ECE centre for carrying out science and mathematics activi- 
ties. It was found that over half (58\%) of the participants had mathematics and science corner in their centres, while only $1 / 3^{\text {rd }}(33 \%)$ indicated that they used the mathematics and science corners on every day, and the rest used up to a maximum of thrice a week only. Interestingly, a very small percentage (9\%) though, indicated that they did not have maths and science corners but engaged children in mathematics and science activities, almost thrice a week, probably by building up an informal set up for doing activities indoors! Another $2 \%$ con- fessed that they never used mathematics and science corner in spite of having it in their centres, and another 3\% disclosed that they neither had such corners, nor engaged in any activities (Figure 5) in their centres.

The findings thus prove that mostly Maths and Science activities are done outdoors and hence, one tends to believe that the teachers encounter with some difficulty in doing them indoors. Perhaps, the teachers do not use maths and science corner due to lack of required skills and competencies! They thus

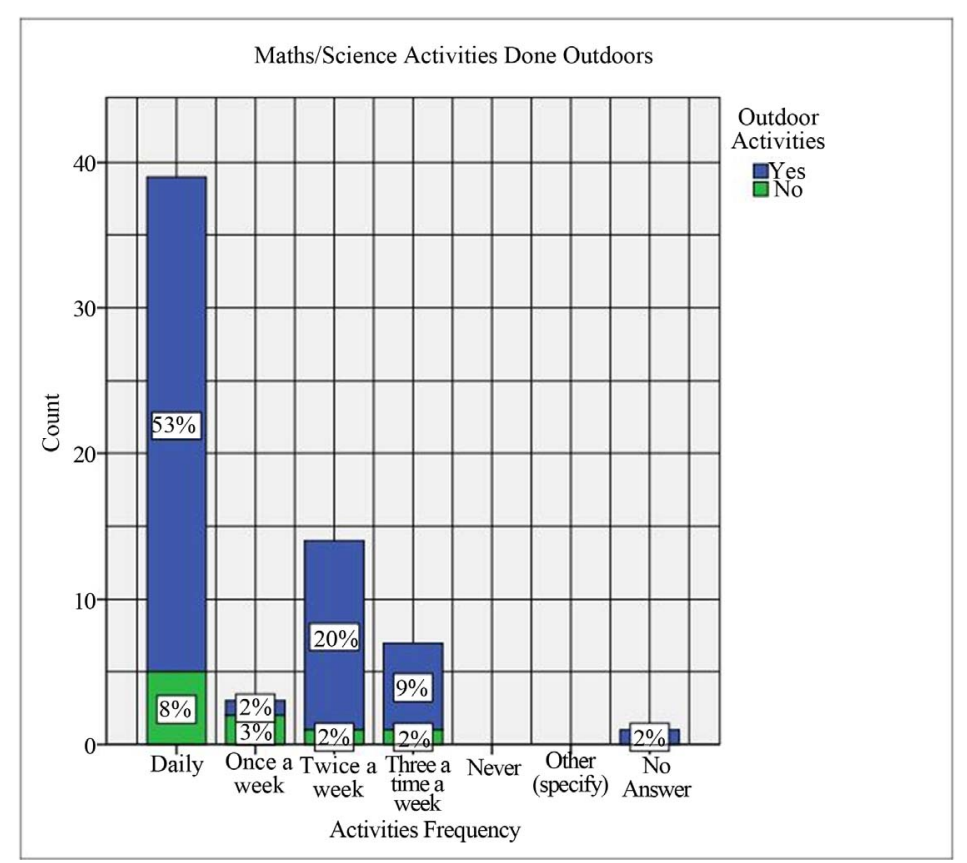

Figure 4.

Activities done outdoors.

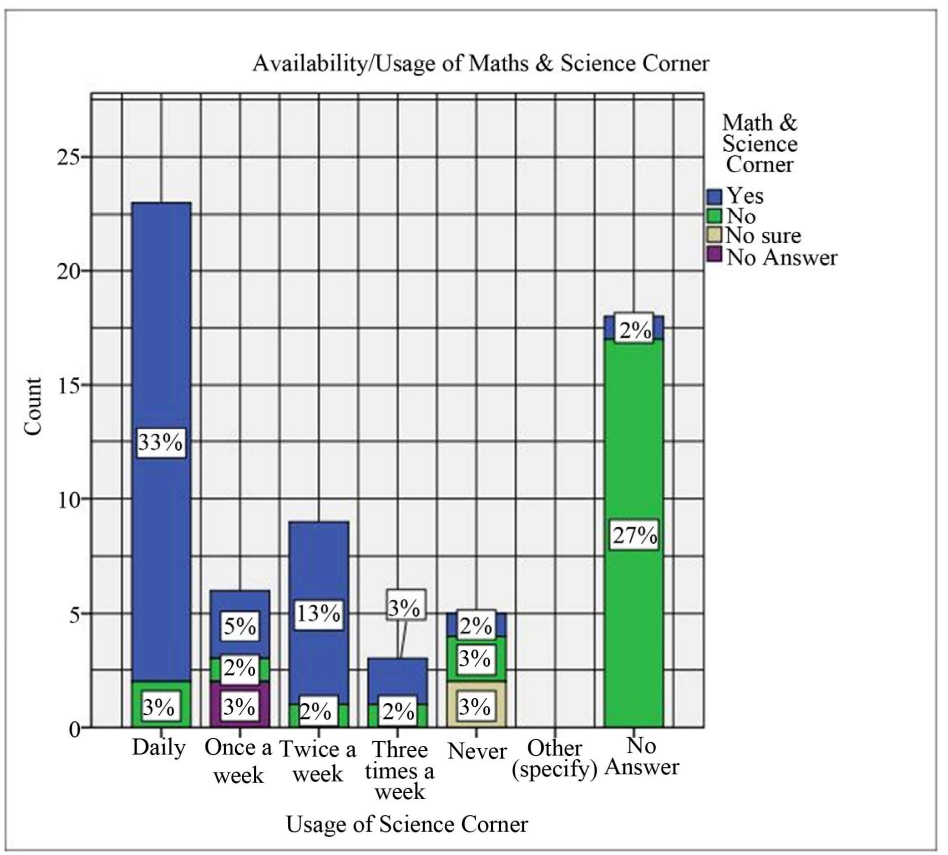

Figure 5.

Maths and science corners. 
need to be empowered with the ability to use them, whereas those who do not have maths and science corner should be provided by the school authorities.

Regarding materials available and their usage, the teachers were asked questions. The above figure shows that the most popular material was magnifiers and 98\% used it. Other commonly used materials included puzzles (77\%), building blocks (73\%), writing materials (53\%), and bottles (52\%). Materials like themed books (44\%) and sand water basin (44\%) were used, but less as compared to others, may be because they are difficult to arrange and cumbersome to handle in the classrooms (Figure 6).

The results also show that inspite of a low interest in science related activities, most of the preschools had magnifiers in the classrooms. May be because magnifiers are easily accessible, cost effective, durable, and entertaining in nature, or they might have been recommended by the EC stakeholders? Other materials, on the other hand, that were necessary for science activities like prisms, weighing scales, balancing scales, magnets were used in an extremely limited way, perhaps due to no inclination towards science activities in pre-schools.

For science teaching, very few engaged in experiments, explorations and observations, water and sand games, field trips, nature walk and spontaneous outdoor play. A limited use of songs/rhymes and water play for teaching of mathematics and science in pre-schools was also revealed.

In the current study the class time-table, teachers' plan books lesson plans and syllabus were also studied and observations were made in the ECE settings. It was however found that the teachers hardly ever planned maths and science activities both indoors as well as outdoors; the teachers' plan book, time-table/class routines also limited the scope of activities related to maths and science. The materials required for science and mathematics activities were also limited in the classroom, and did not quite match with what the teachers indicated!

\section{Challenges Faced and Strategies Used to Overcome Them}

One of the objectives was to find out the challenges and the strategies that the teachers used to overcome the problems. The results took a very interesting turn. It was found that although the majority of teachers claimed to have the knowledge base, $48 \%$ of them faced challenges, while teaching Maths/Science in pre-schools (Figure 7).

On probing further, it was revealed that the challenges were

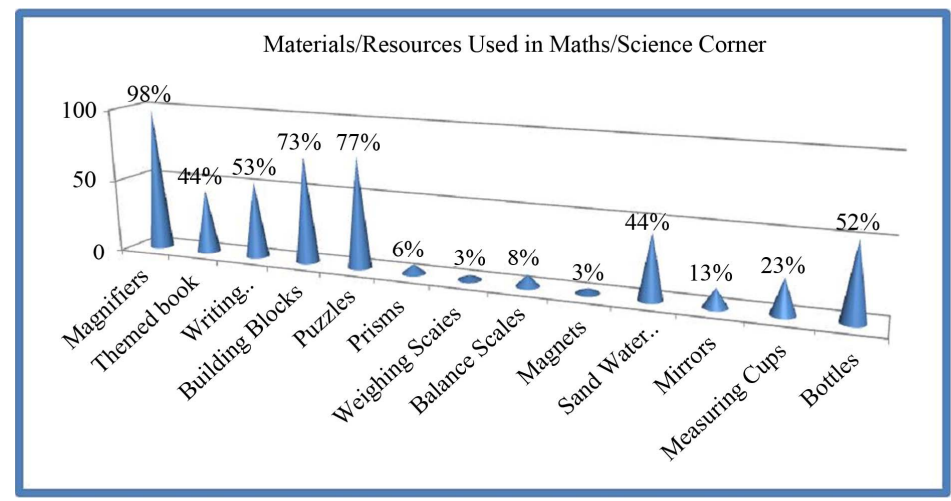

Figure 6.

Usage of materials in maths and science corners.

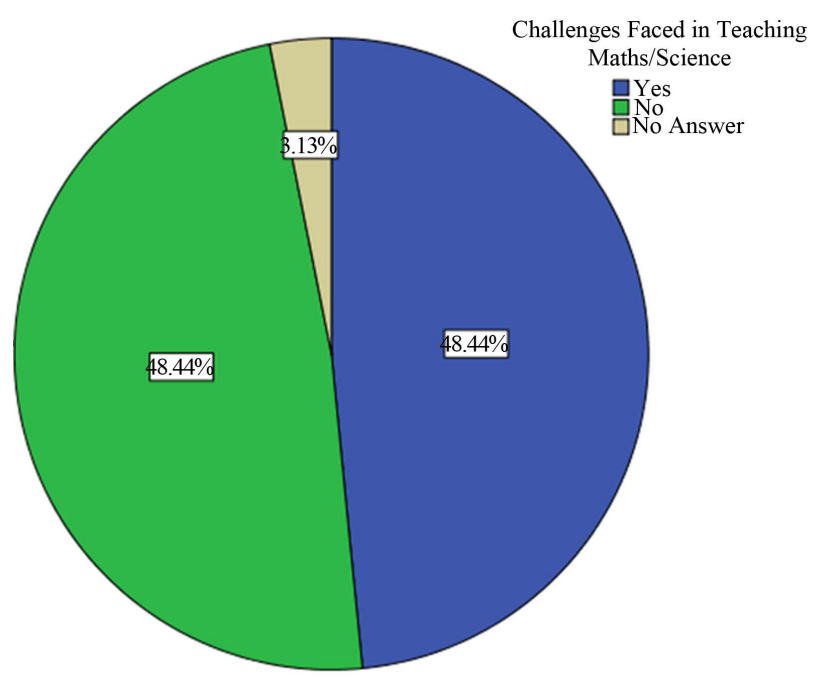

Figure 7.

Challenges faced in maths and science teaching. 
regarding pedagogical aspects, which was indicated in the study, earlier as well. This could thus be attributed to lack of specialised training in ECE. The results also showed that and another $48 \%$ of teachers did not face any challenges. But it was revealed earlier that they mostly remained away from engaging into science and indoor activities. The question thus arises as what exactly happened?

What was the reason for lack of participation in certain activities? Is it the training which failed them to do so, because the study shows no dearth of indoor materials? Or it was simply lack of guidance in pedagogical aspects.

The participants were further asked about the strategies that they use in a bid to overcome the challenges, and it was found that almost $39 \%$ of the respondents used various strategies like varying teaching methods (18\%), restructuring and repeating concepts and activities (8\%), using music and movement (6\%), introducing small and large group activities (3\%), and emphasizing hands on approach (2\%). Besides that, almost all of them used circle time, peer teaching, grouped kids according to their age and ability, performed exercises, introduced remedial lessons, used one to one communication, paid individual attention. Some of the important strategies that enhance child centred methods such as exploration, experimentation and manipulation for example, did not surface in the examples given out clearly by the teachers. This perhaps could be due to lack of training of the pre-school teachers, who did not know the ways of overcoming the challenges.

The teachers and administrators were further asked to identify the areas where teachers need help and the following responses were obtained:

- Relate science to daily activities;

- Create maths and science corners in classrooms;

- Provide adequate resources;

- Engagement in experimentations;

- Sharing ideas with other stakeholders;

- Empowerment of teachers;

- Use real life objects;

- Use varying method like observations, role playing, exploring, investigating;

- Treat subjects with equal importance;

- Let children have fun;

- Rhyme and songs learning.

The above results show that teachers mainly need help in the area of pedagogical knowledge as how to infuse the content and deliver to the children in a most simplistic real life situation, not so much in content areas. It also proves that ECE teachers need empowerment to be able to carry out the daily life activities in the centres, and in turn teach the children the scientific and mathematical concepts at ease. This support could be in the form of some organised workshop, or some short courses or some refreshers' courses, which could empower them with skills to work with the young ones in ECE centres. An idea of a science centre where the children could be taught using varying methods, very basic scientific and mathematical concepts in a very simple and play way method could be well articulated at this juncture. Such a science centre could even be used to train ECE teachers on the usage of basic, real life activities to teach science and mathematics concepts to young children. The teachers could be equipped in a science centre with skills to use experimentation, exploration, and investigative skills to teach these concepts to young children.

The results also emphasise the importance of resources. Pro- vision of mathematics and science corners with appropriate materials could not be undermined. The school's administrations need to take note of such essential resources as today's child needs to gain a wide variety of knowledge and skills in science and mathematics and this can not be achieved without relevant materials, supporting curriculum coupled with teacher competencies and skills!

The results show that the issue of empowerment of ECE teachers is most crucial in Botswana. Currently, most teachers are not qualified or trained in ECE and they need specialised training, and a provision needs to be made both for in-service and pre-service training (Republic of Botswana, 2001). They need to be empowered with teaching of mathematics and science on an equal footing, so that they don't emphasise on mathematics alone. The ECE teachers need to be prepared to do activities indoors, as well as outdoors as they are the catalysts of the learning process and the success of education rests on them (Republic of Botswana, 1994). Perhaps an emphasis on comprehensive specialised training in ECE needs to be made here. Just any teacher training programme cannot prepare them to work with the young ones at various set ups. And a well formulated curriculum is also unavoidable for providing guidance to these teachers, which is currently not available in Botswana.

\section{Conclusion}

The current study gives promising insights pertaining to teaching of mathematics and science in Botswana preschools. To be more specific, activities that develop children's mathematical competence are predominant in Botswana pre-schools, as only a few teachers acknowledged infusing science concepts in their daily curriculum. These teachers' attempts are however, thwarted by the fact that they have limited scope of knowledge with regard to preschool science and hence children's engagement is restricted to fewer science related activities. It is with no doubt that the current practice has a negative bearing on children as science is equally an important school readiness domain (Greenfield, Jirout, Dominguez, Greenberg, Mier, \& Ficillo, 2009). Nevertheless, it is apparent that very few of the teachers are cognizant of various scientific concepts. Hence the overarching questions that remain unanswered are why there is lack of confidence in teaching of science at this level of education?

It is prevalent that the majority of preschools have well prepared mathematics and science corners within their classrooms, but there is a disparity in their usage and the teachers are limited in scope and uncertain about their attempt to develop children's mathematics and science skills.

It is also revealed that Botswana preschool teachers generally prefer to have mathematics and science activities in the outdoors through play, perhaps, because the (Republic of Botswana, 2008):

"Young children are active and curious; they need to explore, discover, ask questions, practice and rehearse in order to build concepts and ideas from their experiences. These activities, which form the building blocks to learning, are brought together during play” (p. 11).

The teacher thus needs to plan and provide as many opportunities as possible for exploration, experimentation and discovery, both indoors and outdoors. This calls for preschool teacher 
preparation and provision of a standard national ECE curriculum.

\section{Recommendations}

ECE teachers need to be trained on teaching mathematics and science as well appropriate use of material resources specific to these domains. Different initiatives like workshops, inservice-training, can be put in place to address this identified deficiency. In addition, a science centre established within the University of Botswana can be quite useful for both pre-service and in-service preschool teachers as they can have free and easy access to the information and hands on practice each time they need it.

Also, there is urgent need to review educator programs offered in the country to establish the extent to which they prepare teachers for teaching mathematics and science. It should be noted that all the recommended options can make a difference in the current status quo and the government should also expedite implementation of the national early childhood curriculum. This will provide a yard stick for teaching mathematics and science in preschool.

\section{Acknowledgements}

The authors would like to acknowledge the Office of Research and Developments (ORD), University of Botswana for extending support and funding this study.

\section{REFERENCES}

Barnett, D.W., VanDerHeyden, A. M., \& Witt, J. C. (2007). Achieving science-based practice through response to intervention: What it might look like in preschools. Journal of Educational \& Psychological Consultation, 17, 31-54.

Bers, M. U., \& Portsmore, M. (2005). Teaching partnerships: Early childhood and engineering students teaching math and science through robotics: ERIC-education resources information centre. New York: Springer.

Bishop, A. J. (1991). Mathematical enculturation: A cultural perspective on mathematics education. The Netherlands: Kluwer Academic Publisher.

Bose, K. (2008). Early childhood care and education programmes in Botswana: Policy (2001) implementation. Asia-Pacific Journal of Research in early Childhood Education, 2, 3-23.

Clements, D. H. (2001) Mathematics in the preschool. Teaching Children Mathematics, 7, 270-275.
Darling-Hammond, L. (2000). How teacher education matters. Journal of Teacher Education, 51, 166-173. doi:10.1177/0022487100051003002

Essa, E. L. (2011). Introduction to early childhood education. Belmont: Wardsworth.

Fu, V. R. (2010). Learning and teaching in preschool. http://www.pbs.org/teachers/earlychildhood/articles/learning.html

Gallenstein, N. L. (2004). Creative discovery through classification (early childhood corner). Teaching Children Mathematics, 11, 103108.

Garbett, D. (2003). Science education in early childhood teacher education: Putting forward a case to enhance student teachers' confidence and competence. Research in Science Education, 33, 467-481. doi:10.1023/B:RISE.0000005251.20085.62

Glasserfeld, V. E. (1989). Cognition, construction of knowledge, and teaching. Syntheses, 80, 121-140. doi:10.1007/BF00869951

Greenfield, D. B., Jirout, J., Dominguez, X., Greenberg, A., Maier, M., \& Fuccilo, J. (2009). Science in the preschool classroom: A programmatic research agenda to improve science readiness. Early Education and Development, 20, 238-264. doi:10.1080/10409280802595441

Johansson, E., \& Pramling Samuelsson, I. (2006). Play and learninginseparable dimensions in preschool practice. Early Child Development and Care, 176, 47-65. doi:10.1080/0300443042000302654

Kallery, M., \& Psillos, D. (2001). Pre-school teachers' content knowledge in science: Understandings of elementary science concepts and of issues raised by children's questions. International Journal of Early Years Education, 9, 165-177. doi:10.1080/09669760120086929

Lehrer, R, \& Schauble, L. (2006). Handbook of child psychology: Scientific Thinking and Science Literacy. USA: John Wiley \& Sons, Inc.

Lind, K. K. (1999). Science in early childhood: Developing and acquiring fundamental concepts and skills. http://www.project2061.org/publications/earlychild/online/experienc e/lind.htm

Moomaw, S. (2011). Teaching mathematics in early childhood. Baltimore: Brookes Publishing Company.

Republic of Botswana (1994). Revised national policy on education. Gaborone: Government Printers.

Republic of Botswana (2001). Early childhood care and education policy on education. Gaborone: Government Printers.

Republic of Botswana (2008). Curriculum Development Division, Curriculum Development and Evaluation Department: Ministry of Education. Gaborone: Government Printers.

Resnick, L. B. (1987). Education and learning to think. Washington DC: National Academy Press.

Wiersma, W., \& Jurs, S. G. (2005). Research methods in education. USA: Pearson.

Witt, S. D., \& Kimple, K. P. (2008). "How does your garden grow?” Teaching preschool children about the environment. Early Child Development and Care, 178, 41-48. doi:10.1080/03004430600601156 